\title{
A case study on the effect of soil compaction on potato growth in a loamy sand soil. 2. Potato plant responses
}

\author{
C. D. van Loon ${ }^{1}$ and J. Bouma ${ }^{2}$ \\ ${ }^{1}$ Research Station for Arable Farming and Field Production of Vegetables, Edel- \\ hertweg 1, Lelystad, the Netherlands \\ ${ }^{2}$ Soil Survey Institute, Department of Soil Physics, Marijkeweg 11, Wageningen, \\ the Netherlands
}

Received:

Key words: potato yield, potato quality, second growth, available water, effective root zone, soil compaction

\section{Summary}

Potato plant reactions to soil compaction were studied in the field in the dry year 1976. Irrigation was applied in some of the treatments.

- Strong compaction of top-soil resulted in shallow rooting, low water availability and relatively slow foliage- and rootgrowth in the first 60 days after emergence, as compared with the non-compacted treatment.

- Compaction of the sub-soil (formation of a plow-pan) initially resulted in relatively rapid foliage growth, which was partly due to a high capillary flux from the water-table; however the rate slowed down as vertical root elongation became inhibited by the plow-pan.

- Top-soil compaction resulted in depressed yields and severe induction of second growth as compared to the not compacted or irrigated treatments.

- At maturity, differences in total yields among treatments were small, except for the treatment with plow-pan where the yield was low; soil compaction affected marketable yield negatively.

- The quantity of available water for the crop, defined as the measured water uptake from the rooted zone and a calculated capillary flux to the rooting front was compared with potential evapotranspiration and significant differences thus obtained among treatments were well reflected by observed differences in vegetative growth.

\section{Introduction}

Potato growth is strongly influenced by soil structural conditions. Timm \& Flocker (1966) found a marked decrease in total yield and an increase in percentage of deformed tubers as a result of increasing soil compaction. Leszynski \& Tanner (1976), 
reviewing literature on rooting capacity of potatoes, conclude that penetration of roots into a plow-pan is very limited if present. But also compaction of the surface soil can have a strong negative effect on yield and quality (McDole, 1975).

In this investigation, potato plant reactions to soil compaction (partly in combination with irrigation) were studied in the field. Associated soil physical aspects were presented seperately in a companion paper (Boone et al., 1978). Reactions studied included growth of roots and foliage, tuber production and tuber quality.

\section{Materials and methods}

On 14 April 1976, mini-sprouted seed of the variety Bintje, size $40-45 \mathrm{~mm}$, was planted with a 4-row automatic planter on rows $75 \mathrm{~cm}$ apart, at distances within the row of $33 \mathrm{~cm}$, on the following treatments of soil compaction on a loamy sand soil (Boone et al., 1978):

L : loose, not compacted (reference)

LI : as L, but with surface irrigation

CM : moderately compacted top-soil

CMI: as CM, but with surface irrigation

CS : strongly compacted top-soil

$P \quad$ : strongly compacted sub-soil (plow-pan).

During the growing season a growth analysis was carried out for all experimental treatments. Length of foliage was determined on 10 and 25 June, 12 July and 16 August. The percentage of ground covered by green foliage was estimated on 4 . 22 and 29 June, 9 July and on 20 September. The weight of the foliage was measured on all treatments, on 14 June and 16 August, whereas tuber weight was determined on 12 July, 16 August and at maturity on 20 September. Foliage- and tuber yields were determined on plots covering the middle two rows of a planters course. At each harvest time 3 plots of $6 \mathrm{~m}^{2}$ each per treatment were dug up. Fresh weight and dry matter content of the foliage were determined, the occurrence of second growth of tubers was assessed as well as the percentage of misshapen tubers. Tubers were graded and the under-water weight* was determined.

Meteorological data for calculation of $\mathrm{E}_{\mathbf{0}}$ were taken from Lelystad-Haven, about $10 \mathrm{~km}$ from the experimental field.

\section{Results and discussion}

\section{Development of the crop}

On 19 May, $80-90 \%$ of the potato plants had emerged, except on treatment CMI with only $70 \%$. Ten days later there was nearly $100 \%$ emergence. Development of the foliage was most rapid on treatment $P$ and treatments $L$ and LI (Table 1).

Strong compaction of the top-soil (treatment CS) resulted in the relatively lowest

* under-water weight $=$ weight of $5 \mathrm{~kg}$ of potatoes in water. 


\section{EFFECT OF SOIL COMPACTION ON POTATO GROWTH. 2}

Table 1. Stem length $(\mathrm{cm})$ and ground coverage by green foliage $(\%)$ during the first part of the growing season.

\begin{tabular}{|c|c|c|c|c|c|c|c|c|}
\hline \multirow[t]{2}{*}{ Treatment $^{1}$} & \multicolumn{4}{|c|}{ Stem length on } & \multicolumn{4}{|c|}{ Ground cover on } \\
\hline & $10 / 6$ & $25 / 6$ & $12 / 7$ & $16 / 8$ & $4 / 6$ & $22 / 6$ & $29 / 6$ & $9 / 7$ \\
\hline L & 22 & 54 & 64 & 76 & 25 & 84 & 85 & 85 \\
\hline LI & 21 & 57 & 89 & 95 & 23 & 90 & 97 & 95 \\
\hline $\mathrm{CM}$ & 19 & 51 & 58 & 72 & 20 & 72 & 76 & 77 \\
\hline CMI & 18 & 59 & 92 & 107 & 20 & 85 & 94 & 95 \\
\hline $\mathrm{CS}$ & 18 & 40 & 51 & 74 & 17 & 54 & 65 & 75 \\
\hline $\mathbf{P}$ & 28 & 52 & 54 & 66 & 25 & 90 & 95 & 95 \\
\hline
\end{tabular}

1 See 'Materials and methods'.

ground cover on 4 June and in relatively lowest weight of foliage on 14 June (Table 2).

After the first irrigation on 10 June, foliage growth was encouraged on treatments LI and CMI.

As a result of the very dry spring (Fig. 1) plants on treatment $L$ showed serious drought stress symptoms from 14 June to 19 June; stems fell apart and the lowest 3-5 leaves wilted. The other treatments did not show such symptoms, although the foliage had a very dark green colour. On 19 and 20 June about $25 \mathrm{~mm}$ rain resulted in an improved crop stand.

However, the period from 25 June to 9 July was very warm with an extremely high evaporative demand $\left(E_{0}\right.$ on average $\left.7 \mathrm{~mm} \mathrm{day}^{-1}\right)$. At the end of June and beginning of July plants on treatment $P$ suffered visibly of drought stress by showing wilting, whereas the other treatments were only darker green in colour.

Table 2. Weight of foliage on 14 June and 16 August $\left(\mathrm{kg} \mathrm{m}^{-2}\right)$.

\begin{tabular}{llllllll}
\hline Date & Yield & L & LI & CM & CMI & CS & P \\
& & & & & & & \\
14 June & fresh weight & 1.11 & 1.24 & 0.96 & 1.15 & 0.51 & 1.31 \\
& dry weight & 0.10 & 0.11 & 0.09 & 0.10 & 0.05 & 0.12 \\
& & & & & & & \\
16 August & fresh weight & 2.22 & 2.85 & 2.41 & 2.91 & 2.26 & 1.42 \\
& dry weight & 0.25 & 0.34 & $\mathbf{0 . 2 8}$ & $\mathbf{0 . 3 3}$ & $\mathbf{0 . 2 8}$ & 0.20 \\
\hline
\end{tabular}

Table 3. Gross tuber yield at three dates during the growing season $(\mathrm{kg} \mathrm{m-2})$.

\begin{tabular}{lllllll}
\hline Harvest date & L & LI & CM & CMI & CS & P \\
& & & & & & \\
12 July & 2.50 & 2.58 & 2.23 & 3.03 & 1.61 & 2.25 \\
16 August & 5.19 & 6.08 & 5.11 & 5.80 & 4.63 & 4.09 \\
20 September & 6.74 & 7.30 & 6.64 & 7.25 & 6.59 & 4.24 \\
\hline
\end{tabular}


Differences in foliage growth during the first part of the growing season, as discussed, were clearly reflected by the results of the first tuber harvest on 12 July (Table 3).

On the first harvest date tuber yields on the irrigated treatments were far better than those on the dry ones, with treatment LI as best and treatment CS far behind. In spite of the better initial growth in treatment $P$, tuber yield at 12 July was already lower compared with treatment L. Around mid July stems on treatment P fell apart, the lowest leaves died, and ground coverage decreased.

\section{Second growth}

Growth restarted vigorously on treatments CM and CS at the end of July, resulting in higher quantities of foliage on these treatments as compared with treatment $\mathbf{L}$ (16 August observations: Table 2). This regrowth of haulms so late in the season was due to both an induction of second growth in the period end June/beginning July, and an improved water supply.

High temperatures, particularly of the underground parts of the potato plant can be the cause of this phenomenon (Bodlaender et al., 1964).

Symptoms of secondary growth are also the sprouting of tubers, followed later in a cooler period by the development of new tubers at the tops of the sprouts.

Underground symptoms of second growth were found abundantly on some treatments in the second week of July. Assuming that high (soil) temperature is the cause of second growth, more symptoms could be expected on treatments CM and CS, as compared with treatments $L$ and $P$ because the former two treatments had a lower ground coverage of foliage in early July (Table 4) and the soil temperature in exposed dry soil will be raised highest by radiation. Irrigation, which causes a higher soil moisture content, will form an additional limitation for a raise in temperature. This was confirmed by counts of sprouted tubers at the harvest of 12 July where treatments LI and CMI had no second growth, where treatments L and $\mathbf{P}$ were intermediate and where highest values were found for treatments CM and CS (Table 4).

Table 4. Relation of ground coverage by foliage and the occurrence of second growth.

\begin{tabular}{lrrrrrr}
\hline & L & LI & CM & CMI & CS & P \\
Ground coverage at 29 June (\%) & 85 & 97 & 76 & 94 & 65 & 95 \\
Tubers with sprouts at 12 July (\%) & 18 & 0 & 40 & 0 & 70 & 0 \\
\hline
\end{tabular}

Tuber production in the second part of the growing season

During the period 12 July to 16 August, the production rate was about the same for all treatments, except for $P$, which had a much slower rate due to early senescence (Table 3). Senescence showed by a gradual yellowing and dying of leaves. 
Due to second growth plants on treatments CM and CS had a top with relatively young leaves, during the last part of the growing season. This resulted in relatively late senescence and highest production in the period 16 August to 20 September. The sequence of senescence for the different treatments was: P - CMI - LI - L CM - CS. On 20 September still $20 \%$ of the ground was covered by green foliage on treatment CS, whereas less than $5 \%$ was found for the other treatments.

Final yield differences among treatments in September were smaller than those measured in the middle of August, except for treatment P (Table 3). Highest yields were obtained from the irrigated treatments.

\section{Tuber quality}

Second growth affects tuber quality unfavourably (Table 5). It often results in smaller average tuber size, tuber deformation, and a lower dry matter content (van der Zaag, 1958; Lugt, 1960).

Sometimes tubers of the first generation (primary tubers) on which new (secondary) tubers have been formed become glassy and consequently unedible (van der Zaag, 1958).

The occurrence of primary tubers on which secondary tubers have been formed, is in agreement with the observed sprouting of tubers as shown in Table 4 . The

Table 5. Primary tubers with secondary tubers and misshapen tubers at the final harvest, exposed as a percentage of primary tubers.

\begin{tabular}{lclc}
\hline Treatment & $\begin{array}{l}\text { Primary tubers with } \\
\text { secondary tubers }(\%)\end{array}$ & $\begin{array}{l}\text { Misshapen tubers } \\
(\%)\end{array}$ & $\begin{array}{l}\text { Total } \\
(\%)\end{array}$ \\
L & 18 & 1 & 19 \\
LI & 0 & 1.5 & 1.5 \\
CM & 39 & 2 & 41 \\
CMI & 1 & 5.5 & 6.5 \\
CS & 56 & 2 & 58 \\
P & 6 & 0 & 6 \\
\hline
\end{tabular}

Table 6. Gross yields at maturity (20 September harvest) divided into marketable yields and culls $\left(\mathrm{kg} \mathrm{m}^{-2}\right)$ and under-water weight of gross yields $(\mathrm{g})$.

\begin{tabular}{lllllll}
\hline $\begin{array}{l}\text { Treat- } \\
\text { ment }\end{array}$ & $\begin{array}{l}\text { Gross } \\
\text { yield }\end{array}$ & $\begin{array}{l}\text { Small } \\
\text { tubers } \\
<35 \mathrm{~mm}\end{array}$ & $\begin{array}{l}\text { Misshapen } \\
\text { tubers }\end{array}$ & $\begin{array}{l}\text { Green } \\
\text { tubers }\end{array}$ & $\begin{array}{l}\text { Market- } \\
\text { able } \\
\text { yield }\end{array}$ & $\begin{array}{l}\text { Under- } \\
\text { water } \\
\text { weight }\end{array}$ \\
L & 6.74 & 0.29 & 0.25 & 0.10 & 6.10 & 402 \\
LI & 7.30 & 0.36 & 0.62 & 0.08 & 6.24 & 433 \\
CM & 6.64 & 0.51 & 0.51 & 0.14 & 5.72 & 417 \\
CMI & 7.24 & 0.34 & 1.08 & 0.15 & 5.68 & 430 \\
CS & 6.59 & 0.65 & 0.46 & 0.33 & 5.06 & 392 \\
P & 4.24 & 0.74 & 0.09 & 0.04 & 3.71 & 431 \\
\hline
\end{tabular}


only exception is treatment $P$ which had no sprouts on 12 July and $6 \%$ primary tubers with secondary tubers in September. This change was due to a second induction of second growth in early August. Contrary to the other treatments, $\mathrm{P}$ had a limited ground cover by foliage at that time (about $50 \%$ ).

In Table 6 gross yields are divided into marketable yield and culls (small tubers $<35 \mathrm{~mm}$, misshapen and green tubers).

Differences among treatments in terms of marketable yield are much more pronounced than those in terms of gross yield. On compacted soil marketable yields are relatively low as a consequence of more small tubers (following second growth) as well as more misshapen tubers. Even with irrigation (treatment CMI) soil compaction seems to have an unfavourable effect on tuber form. Second growth caused a decrease of the under-water weight on treatments CS, L and CM.

\section{Available water and crop growth}

Vertical root elongation was inhibited in the compacted soil treatments (Boone et al., 1978) and this influenced water uptake, as will be demonstrated for treatments $\mathrm{L}, \mathrm{P}$ and $\mathrm{CS}$.

A comparison wil be made of the potential evapotranspiration, the calculated quantity of available water for the crop and crop growth. Potential evapotranspiration was calculated according to Penman (1956) with the formula $E_{p}=f E_{0}$ where $f$ is a reduction factor with values ranging from 0.4 to 0.9 depending on ground coverage by the crop (Hellings, 1971).

$E_{o}$ the evaporation of open water, was calculated empirically, according to Penman (1948). The quantity of available water for the crop (AW) was estimated for successive periods of one week and was derived from two sources. First, the volume of water was estimated which was absorbed in the root zone. The root zone was considered to be a closed system with no vertical water movement beyond its lower boundary. Weekly measurements of the soil water content for each $10 \mathrm{~cm}$ depth increment were used to calculate changes in the volume of water present. Decreases were attributed to uptake by roots. The volume of water in the root zone increased during two weekly periods as a result of rainfall. However, average pressure potentials at the lower boundary of the root zone remained sufficiently low to not allow downward vertical water movement beyond the root zone. Water uptake by the roots in these two periods was estimated by analysing the rainfall patterns during the week. The first $3 \mathrm{~mm}$ of each shower was neglected because of assumed crop interception and evaporation. The remainder of the rain, if any, was assumed to infiltrate (Fig. 1a). Crop uptake (U) in $\mathrm{mm}$ was estimated by: $\mathrm{U}=$ $\mathrm{P}-\triangle \mathrm{M}$ where $\mathrm{P}=$ total precipitation during the week minus $3 \mathrm{~mm}$ for each shower. $\triangle M=$ increase of the total volume of water within the root zone during the week. This approximate analysis is adequate only for weather conditions in the dry year 1976 when only a few showers occurred.

Second, the magnitude of the capillary flux from the water-table to the lower boundary of the rooting zone was estimated with the water-table and the average pressure potential at the lower boundary of the root zone as physical boundary 


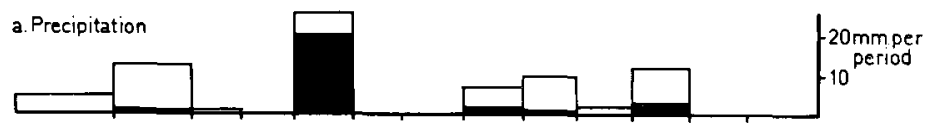

b. Loose soil (L)

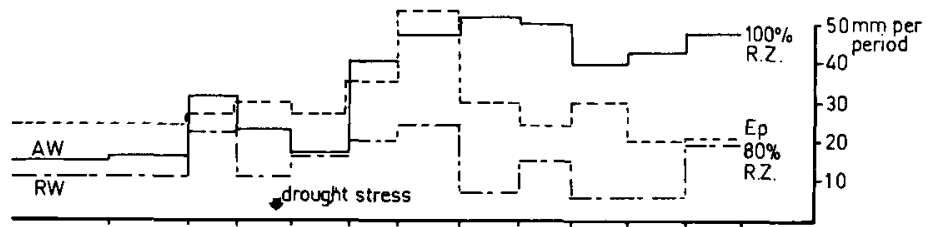

c. Strongly compacted subsoil (P)
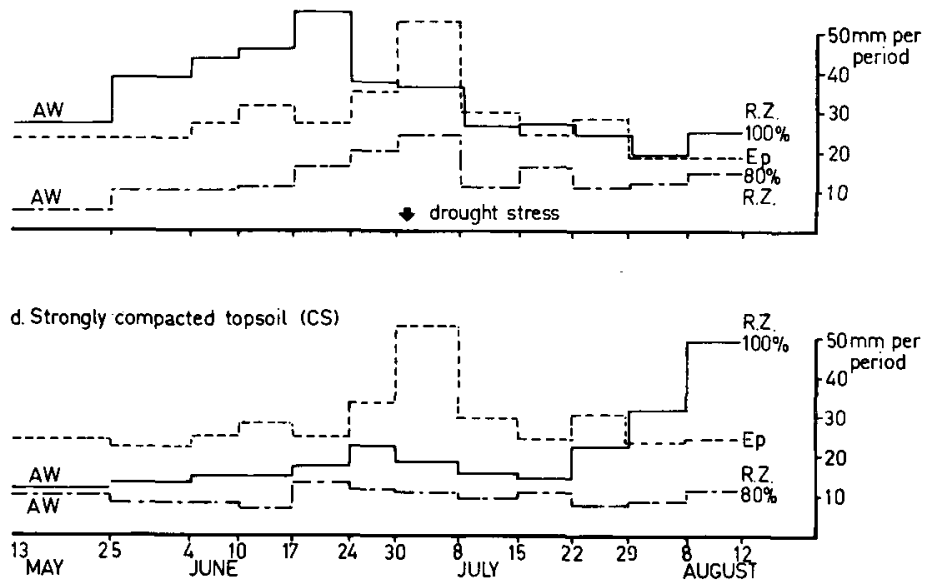

Fig. 1. Potential evapotranspiration $\left(E_{p}\right)$ compared to the calculated quantity of available water for the crop (AW) for a rooting depth above which $80 \%$ of all roots $(80 \% \mathrm{RZ})$ and $100 \%$ of all roots $(100 \% \mathrm{RZ})$ were present (diagrams $b, c$ and d). Curves are shown for treatments $\mathrm{L}$, $P$ and CS. Precipitation per period is shown in diagram a which also includes the effective precipitation (black area in diagram) that was assumed to be available for water uptake in the rooted volume of soil (see text).

conditions. Use of a graphical technique allowed an estimate of fluxes through more than one layer of soil (Boone et al., 1978; Bouma, 1977). Curves for $E_{p}$ and AW are shown in Fig. 1. Calculations were made for a rooting depth above which $80 \%$ of all roots were present ('effective' rooting zone) and for the maximum depth of rooting $(100 \%)$.

Loose soil, not compacted (treatment $L$ ). The quantity of soil moisture available for the crop, considering the $80 \%$ root level, is far below $E_{p}$ (Fig. 1b). Calculations of AW with the depth of maximum penetration of roots results in sufficient water 
available for most periods. The development of the crop from emergence up to about 10 June was quite normal, without abundant haulms. In the week from 14-20 June plants suffered visibly from severe water stress. After 20 June ( $25 \mathrm{~mm}$ of rain) the crop recovered and did not show severe drought symptoms thereafter, not even in the period from 24 June to 8 July when evapotranspiration was unusually high. These reactions of the crop correspond rather well with the calculated AW curve. Rapid penetration of roots in treatment $\mathrm{L}$ maintained a relatively small distance between rooting front and watertable during the entire growing season, allowing considerably upward capillary transport of water. The only loss of contact occurred in the period 14-19 June when the relatively low capillary transport allowed by the uncompacted subsoil did not allow adequate moisture supply (Boone et al., 1978).

Strongly compacted sub-soil (treatment P). According to Fig. 1c (100\% root zone) more water was available in treatment $P$ than in $L$ in the first month after emergence. This was reflected by a more abundant haulm development on treatment $P$ (Tables 1 and 2). By using the $80 \%$ root zone data this difference in foliage growth cannot be explained. On treatment $\mathbf{P}$ the crop showed drought stress at the end of June. The $100 \%$ line in Fig. 1c shows a decreasing availability of water in that period and in the time afterwards. This resulted in relatively early senescence and a low tuber production rate after the first decade of July.

Relatively high capillary transport through the plow-pan resulted in a relatively high moisture supply early in the season. However, roots hardly penetrated the plow-pan and significant capillary transport between the groundwater and the lower boundary of the root zone could not be maintained as the watertable dropped later in the season (Boone et al., 1978).

Strongly compacted top-soil (treatment CS). From emergence up to the end of July the availability of water for the crop on this treatment was limited (Fig. 1d). This was reflected clearly by the vegetative growth (Tables 1 and 2) which showed the lowest values for stem length, ground cover, yield of foliage (14 July) and tuber yield (12 July). After the end of July roots penetrated so deep that the quantity of available water for the crop increased gradually to a level higher than the evaporative demand (100\% root zone). Foliage growth was stimulated vigorously from this time on, partly as a result of second growth, and the tuber production rate increased. At the time of the second harvest (16 August) the difference in yield between treatments $\mathrm{L}$ and CS was already $50 \%$ less than as observed during the first harvest (Table 3).

Mechanical resistance of the compacted top-soil retarded vertical root growth early in the season and this resulted in lack of significant capillary transport between the groundwater and the lower boundary of the root zone. However, capillary transport could be established as soon as roots penetrated the top-soil, reaching the subsoil (Boone et al., 1978).

Level and fluctuations of the AW curves (100\% root zone) for treatments $\mathrm{L}, \mathrm{P}$ and $\mathrm{CS}$ are in good qualitative agreement with crop reactions but they appear to slightly over-estimate the volume of available moisture. 
The definition of an 'effective' root zone in terms of the layer above which $80 \%$ of the roots are present, is not satisfying on the basis of these experiments which suggest - at least for conditions in 1976 - the definition of the 'effective' root zone for potatoes in terms of the depth of the soil layer above which approx. $90 \%$ of the roots occur.

\section{Acknowledgment}

The authors are indebted to $\mathrm{Mr}$ J. F. Houwing who supervised the potato field experiments and assembled experimental data.

\section{References}

Bodlaender, K. B. A., C. Lugt \& J. Marinus, 1964. The induction of second-growth in potato tubers. Eur. Potato J. 7: 57-71.

Boone, F. R., J. Bouma \& L. A. H. de Smet. 1978. A case study on the effect of soil compaction on potato growth in a loamy sandy soil. Neth. J. agric. Sci. 26: 405-420.

Bouma, J., 1977. Soil survey and the study of water in unsaturated soil. Simplified theory and some case studies. Soil Survey Papers No 13. Soil Survey Institute, P.O. Box 98, Wageningen, $107 \mathrm{pp}$.

Hellings, A. J., 1971. Het verband tussen waterverbruik en opbrengst bij gewassen met duidelijk te onderscheiden gevoelige perioden. Rijkslandbouwconsulentschap voor bodem- en bemestingsvraagstukken, Wageningen.

Lesczynski, D. B. \& C. B. Tanner, 1976. Seasonal variation of root distribution of irrigated, field-grown Russet Burbank potato. Am. Potato J. 53: 69-78.

Lugt, C., 1960. Second-growth phenomena. Eur. Potato J. 3: 307-324.

McDole, R. E., 1975. Influence of cultural practices and soil compaction on yield and quality of potatoes. Am. Potato J. 52: 285-286. (Abstract of Conference paper.)

Penman, H. L., 1948. Natural evaporation from open water, bare soil and grass. Proc. Roy. Soc. A. 193: 120-146.

Penman, H. L., 1956. Evaporation: An introductory survey. Neth. J. agric. Sci. 4: 9-29.

Timm, H. \& W. J. Flocker, 1966. Responses of potato plants to fertilization and soil moisture tension under induced soil compaction. Agron. J. 58: 153-157.

Zaag, D. E. van der, 1958. Doorwas in aardappelen in 1957. Landbouwvoorlichting 15: 588-599. 